\title{
Shell Selection of the Hermit Crab, Pagurus longicarpus Say (Crustacea: Decapoda: Paguroidea), in Response to Acid-Treated Shells: A Laboratory Study ${ }^{1}$
}

\section{William $\mathrm{Ye}^{2}$}

\begin{abstract}
Because of increased human-generated carbon emissions, ocean acidification is beginning to dissolve structures built by calcification, including the shells that all species of hermit crab (Crustacea: Decapoda: Paguroidea) use for protection. Since hermit crabs have been known to non-randomly select shells that best fit, this study explores whether the Atlantic long-clawed hermit crab, Pagurus longicarpus Say, 1817 preferentially chooses sturdier, intact shells when provided a choice between untreated shells (control) and acid-treated shells. Under controlled conditions (i.e., removal of stress from predator presence/effluent and intraspecific competition), not-surprisingly, most $P$. longicarpus preferred non-acid treated (control) shells by the end of testing period ( 1 hour) over heavily acid-treated shells; there was no statistical difference between the control shells and lightly acid-treated shells.
\end{abstract}

Key Words: Shell selection, behavior, hermit crabs, Pagurus longicarpus, Crustacea, Decapoda, Paguroidea, Paguridae, pagurids, acid-treated shells, increased, humangenerated carbon emissions, global climate change, drill vibrations removal method for hermit crabs in shells

\section{Introduction}

Increased anthropogenic carbon emissions have led to rapid ocean acidification and carbonate depletion that has slowed, and even reversed, calcification, especially in colder waters (Leung et al. 2017, Singer 2016). Calcified structures that can no longer repair this damage (i.e., dead hard corals and vacant gastropod shells) are particularly susceptible to dissolution, leaving species that rely on these resources, like paguroids (hermit crabs), vulnerable to predation and osmotic stress (Bibby et al. 2007). In both the near and distant future, ocean acidification is expected to worsen. Studies show that the ocean's $\mathrm{pH}$ has dropped 0.1 units since the Industrial Revolution (Hoegh-Guldberg and Bruno 2010, Zeebe et al. 2008), while estimates predict another $0.2 \mathrm{pH}$ unit decrease by the year 2100, further exacerbating carbonate depletion (Vézina et al. 2008, Busch et al. 2014). Even though the direct influences of carbonate depletion and ocean acidification have been identified in numerous studies (e.g., Orr et al., 2005), little research has been done to observe their effects on hermit crab shell selection.

\footnotetext{
${ }^{1}$ Submitted on April 15, 2019. Accepted April 22, 2019. Last revisions received on April 30, 2019.

${ }^{2}$ Cambridge, Massachusetts, USA. E-mail: willye0513@gmail.com .
} 
In sharp contrast to most arthropods, hermit crabs (Decapoda: Paguroidea), have a large, unsclerotized, soft abdomen (Figure 1A). All species described, including the long-clawed hermit crab, Pagurus longicarpus Say, 1817 (Figure 1B), generally use empty, calcified gastropod shells as protection from both biotic and abiotic threats after metamorphosing into their adult forms (Hazlett 1981, De la Haye et al. 2011).
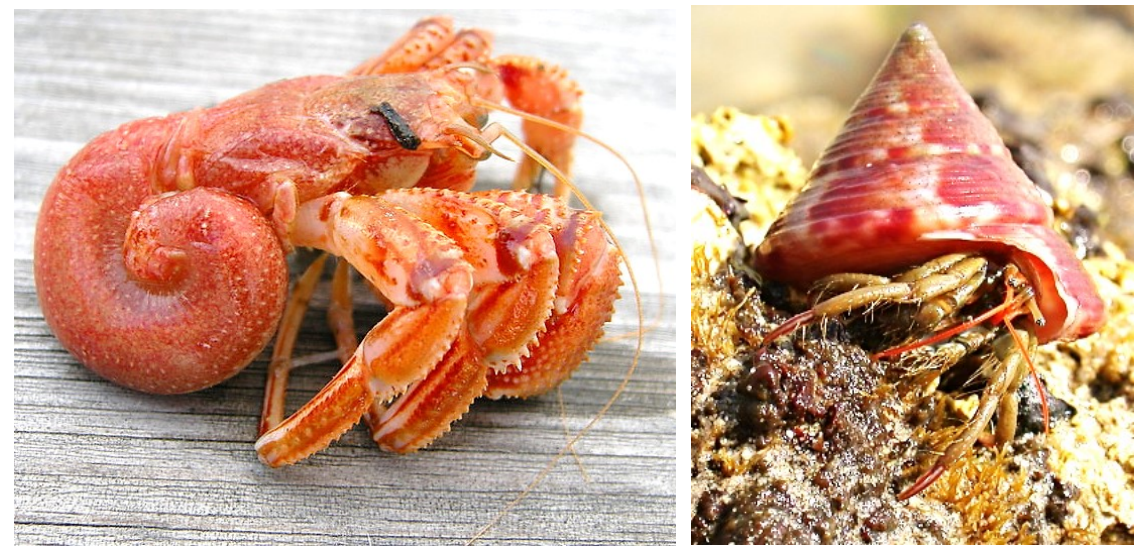

Figure 1. Hermit crabs, Pagurus sp. A. Naked, or shell-less, P. bernhardus (Linnaeus, 1758) imaged in Stavern, Norway. Photo by Arnstein Rønning. https://commons.wikimedia.org/wiki/File:Pagurus bernhardus.JPG B. Pagurus longicarpus Say, 1817 within a Calliostoma sp. (Gastropoda: Calliostomatidae) shell. Source: http://mediateca.educa.madrid.org/imagen/ver.php?id_imagen=wkws4jooq6s4ygn6\&id_grupo $\underline{=211}$. Author: Banco de imágenes del CNICE-MEC.

This portable shelter is so important to these organisms' evolutionary fitness that shell availability is known to be one of the limiting factors influencing hermit crab population dynamics (Carlon and Ebersole 1995). Furthermore, these crustaceans have been shown to selectively occupy shells that best fit and protect their soft abdomens (Pechenik and Lewis 2000). Since these shells neither expand as the crab's body grows nor do the hermit crabs repair any damage suffered during use, hermit crabs are frequently searching for potential replacement shells throughout their adult lives, particularly as they molt into a larger sized organism (Hazlett 1981). So intense can the competition for shells among hermit crabs be, that the presence of empty shells in is uncommon (Anonymous 2015, 2018). Shells that have been weakened or compromised in any way will be exchanged for those that are more suitable for the individual (Rotjan et al. 2004). As a species that both live in oceans and rely on non-regenerative calcified structures for habitat, the long-clawed hermit crab is an ideal model species for studying shell selection in the context of ocean acidification. 


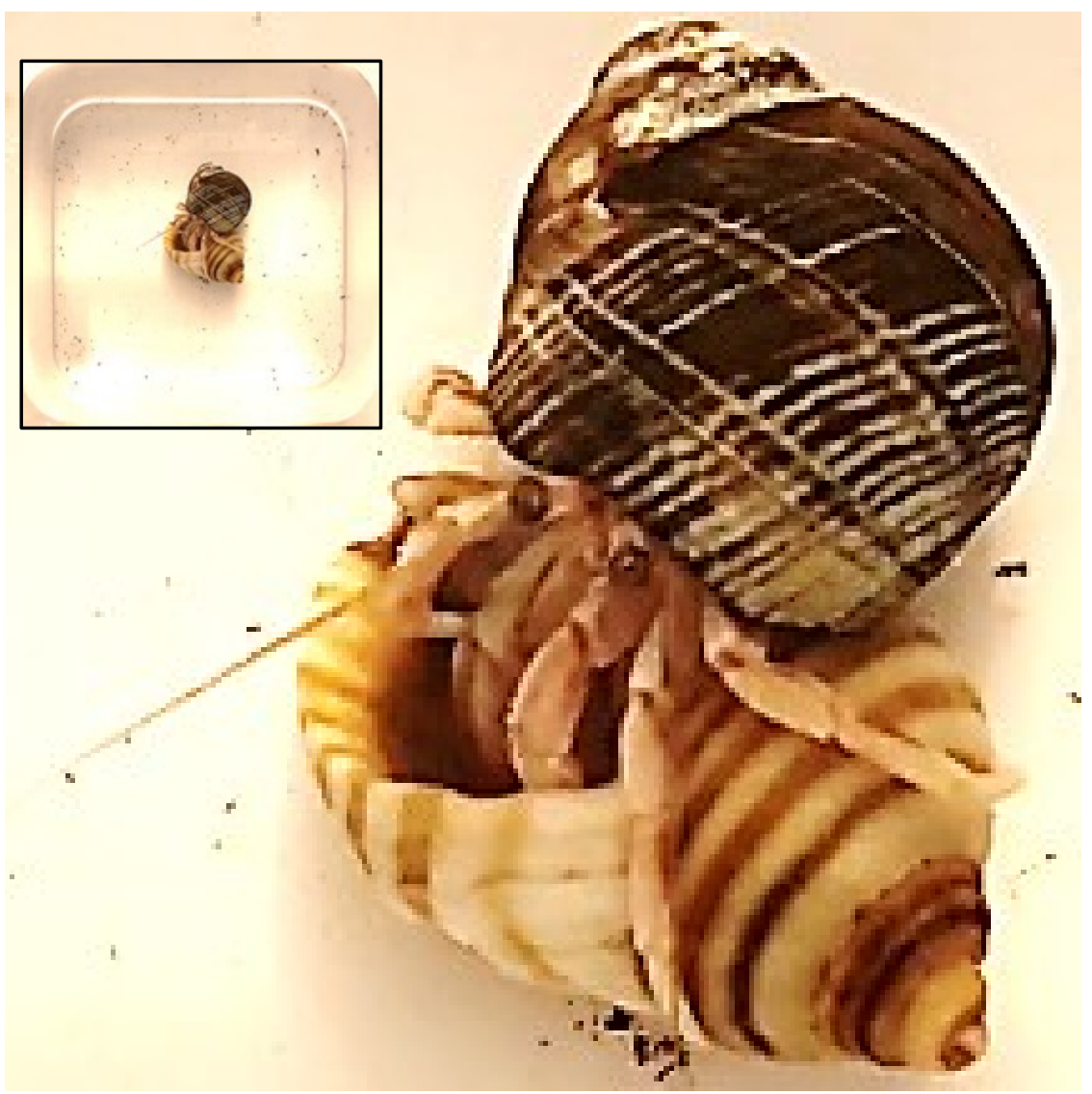

Figure 2. Pagurus longicarpus hermit crab exploring an empty shell (bottom). Insert is an example of the plastic arena used, side dimensions $7.5 \mathrm{~cm}$.

In this study, I examined shell preference of the long-clawed hermit crab, $P$. longicarpus, by providing shell-less, herein also called naked, hermit crabs either an acid treated (experimental) or an untreated, intact shell (control). Given that hermit crabs tend to occupy the most protective shells available (Carlon and Ebersole 1995, Pechenik and Lewis 2000, Rotjan et al. 2004), I expect to see individuals avoiding acid treated shells after shell investigation.

\section{Methods}

\section{Hermit crab collection and rearing}

Twenty-four adult (unidentified sex) $P$. longicarpus hermit crabs with shells were purchased from VWR (Item \# 470180-324). The shells were carefully 
removed from the hermit crabs (Figure 3). Upon arrival, P. longicarpus were housed individually in $16 \mathrm{oz}$. (circa $473 \mathrm{ml}$ ) deli containers in Instant Ocean seawater (mixed to $30 \mathrm{ppt}$ ) at approximately $15^{\circ} \mathrm{C}$. Hermit crabs were held at least two weeks before experimentation to allow the animals to acclimate to their new rearing conditions. Only $P$. longicarpus crabs that exhibited normal behavior (i.e., readily eating frozen mysis shrimp; mysis shrimps are a type of shrimp-like crustaceans), along with no missing chelipeds, legs, or antennae were used for the experiments since stress and tactile cues have been shown to be critical factors for shell investigation and selection (Rotjan et al. 2004). Individual hermit shell-less crabs used for this experiment weighed 0.7 to $1.6 \mathrm{~g}$.

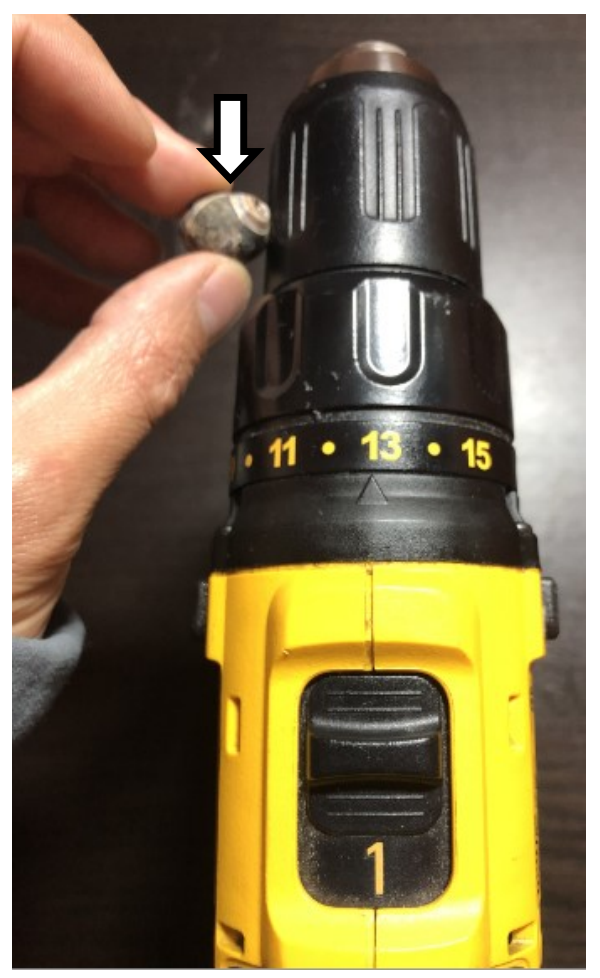

\section{Hermit crab removal from shells}

Individual $P$. longicarpus were removed from their shells by holding the shell up to the "chuck" of a handheld power drill (Figure 3). By creating vibration bursts (from as little as 10 bursts, up to hundreds spread across multiple days) of up to five seconds long causes the crabs to eject themselves. Since hermit crabs are known to fight over ideal shells by vigorously shaking the competition, also known as "shellrapping" (Briffa 2006, Gherardi 2006), this removal method seems to be the least invasive and stressful for the test subjects.

Figure 3. Holding a shell (arrow) containing a hermit crab gently touching the chuck of a power drill causes hermit crabs to eject themselves from the shell.

\section{Littorina littorea shell garnering for host shell selection experiments}

One hundred empty common littorinid periwinkle, Littorina littorea (Linnaeus, 1758) shells (Gastropoda) $15-25 \mathrm{~mm}$ long were collected by hand from Nantasket Beach in Hull, Massachusetts in October 13, 2018. Since $P$. longicarpus are most commonly observed occupying shells of $L$. littorea in the wild, only these shells were used for this experiment (Pechenik and Lewis 2000). To make sure that all the empty shells provided would be the correct fit 
to $P$. longicarpus original shells, only shells with the most similar aperture (opening) width and shell height to those the hermit crabs last inhabited were used for the experiments. Differences between inhabited and experimental shell aperture width and length were no more than $3 \mathrm{~mm}$ for all tests.

\section{Acid treatment of the Littorina littorea shells}

The L. littorea sized shells were either left untreated, placed in $5 \%$ hydrochloric acid $(0.605 \mathrm{M})$ for 1 minute to (presumably) change the texture of the shell (lighter acid damage), or left in 5\% hydrochloric acid (0.605 M) for 10 minutes (heavier acid damage). Light acid treatments would mimic damage incurred under current ocean acidification (minor damage due to exposure from slightly acidic conditions), while major acid damage from these treatments would resemble damage from long-term exposure of more acidic waters. All shells with light acid damage had their total mass change by less than $5 \%$, while those that experienced heavy acid damage had total mass changes ranging between 19 to $32 \%$. Similarly, internal volumetric testing using syringe showed a less than $2 \%$ decrease in internal structure for lightly treated shells, while those treated for 10 minutes showed changes between 7 to $10 \%$. Shells in which holes appeared after treatment were not included for this study since $P$. longicarpus is known to discriminate against shells with holes (Pechenik and Lewis 2000). Smaller shells that were less than $5 \mathrm{~mm}$ across were especially susceptible to this type of damage and, along with the hermit crabs that inhabited shells of this size, were excluded from these experiments.

Treated shells were soaked in mixed seawater that was identical to both holding and testing conditions for 24 hours to ensure removal of all acid before experimentation began.

\section{Experimental conditions of the host shell selection experiments}

Naked hermit crabs were placed in an isolated, darkened housing container for 1 hour prior to testing to minimize impulsive, non-selective behavior. Two different choice experiments were performed. Twenty shell-less $P$. longicarpus (10 per experiment), completely submerged in artificial seawater, were each placed in different $7.5 \mathrm{~cm} \times 7.5 \mathrm{~cm}$ plastic arenas, one hermit crab with one untreated shell and one shell that was exposed to either light or heavy acid damage (Figure 2). Each round of experiments lasted 60 minutes, not including the amount of time before initial shell selections were made. The experiments, which were ran sequentially, took 20-25 hours and were performed during six consecutive days. Naked $P$. longicarpus were first positioned in the center of the testing container, while the shells were specifically placed on opposite corners of the testing container, ensuring that the crabs have the same odds of initially encountering intact or acid-treated shells. Individuals took between 12 seconds and 13.7 minutes to make their first selections. Observations detailing which of the two types of shells were occupied were recorded for each hermit crab at the 
$1,2,5,10,20,30,45$, and 60 minutes time points beginning immediately after a shell was first occupied. More frequent time points at the beginning of experimentation were selected in order to catch the more frequent switching that occurs after initial shell selection. The final time point (60 minutes) was chosen because previous studies showed that final shell choices were generally made within 1 hour (Pechenik and Lewis 2000).

\section{Videotaping and Microphotography}

Video recording was done by anchoring an iPhone 8 directly above the plastic arenas with about $15 \mathrm{~cm}$ of clearance.

Microphotography of a sample of different types of $L$. littorea shells types (control, lightly acid-treated, and heavily acid-treated, Figure 5A-I) were taken with an Olympus DSX 100 photomicroscope equipped with stacking capabilities. Stacking reconstructs focused images with increased depth of field. Photoshop was used to improve the brightness and contrast of the images.

\section{Data Analyses ${ }^{3}$}

For each of the two experiments, a Cochran-Armitage test, available in R, was performed to determine whether the observed responses of the $P$. longicarpus hermit crabs to the control or to the acid-treated L. littorea shells (a binomial variable), were compatible with a trend (decreasing or increasing) across a single factor, time, the ordinal variable. The null hypothesis is that there was no trend; the alpha value was set at 0.05 .

\section{Results}

The number of adult $P$. longicarpus hermit crabs used was limited (10 per treatment, 20 total), hence, the results herein reported (Figure 4) must be treated as preliminary. Pagurus longicarpus hermit crabs shell preferences within the first few minutes appear to be random, leading to about equal percentage of occupation of the control vs. acid treated shells (Figure 4). Switching shells continued thereafter although to a lesser extent.

Adult $P$. longicarpus behavior was compatible with a trend to increase their preference for untreated (or control) shells over heavily acidified shells (Figure $4, \mathrm{p}=0.04735$, red line). However, adult $P$. longicarpus demonstrated no trend through time in their choices lightly acidified from the control shells (Figure 4, p $=0.05713$, blue line).

\footnotetext{
${ }^{3}$ The reviewers and statisticians that addressed the appropriate ways to analyze the data suggested a variety of non-parametric and parametric tests. Because the grand total of hermit crabs per experiment was only ten individuals, the expected values vary through time, and the data come from a binomial distribution (only two choices - categorical data - were available to the hermit crabs, namely untreated shells or acid-treated Littorina littorea shells), I considered non-parametric tests, and this one in particular, more appropriate.
} 


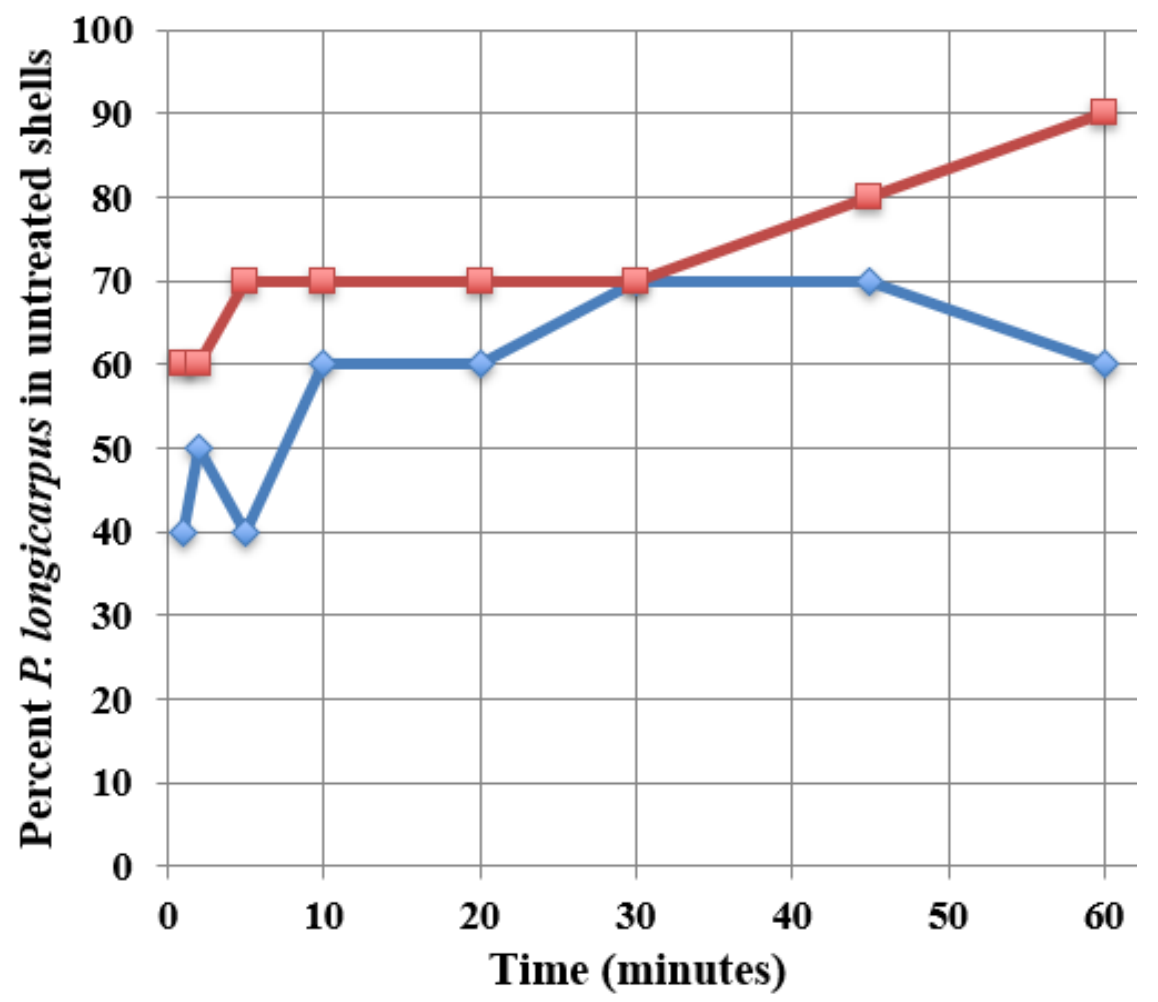

Figure 4. Percent of tested Pagurus longicarpus hermit crabs occupying intact, untreated shells (control) throughout the duration of the two experiments $(\mathrm{n}=10$ different hermit crabs for each of the experiments, total hermit crabs $=20$ ). The experiments, which were ran, consecutively concluded at 60 minutes. The blue line represents the experiment where the hermit crabs were offered a choice between lightly acidified shells or untreated shells; the red line represents the experiment where the hermit crabs were offered a choice between heavily acidified shells or untreated shells.

Representative videos ${ }^{4}$ show shell selection of $P$. longicarpus in the laboratory. They include the investigation of shells and the physical switching of shells. Video 1 shows an individual hermit crab switching between the two offered shells twice (at 1'40" and 2'20"). Video 2 shows the same hermit crab making a final shell choice. This hermit crab did not switch after 1'02".

In these tapes, a $P$. longicarpus hermit crab appears to be touching the inner surface of the shell on the aperture region of the potential new host shell with

\footnotetext{
${ }^{4}$ The videos are located in the following links: https://blaypublishers.files.wordpress.com/2019/05/ye video1.mov and https://blaypublishers.files.wordpress.com/2019/05/ye video-2.mov . The quality of the videos of the actual experiments was not as clear as I would have liked. The linked videos were taken with one of the extra $P$. longicarpus hermit crabs and two different shell types.
} 
the first pair of antennae. Additional "manipulation" of the shell is assisted by the walking legs, including chelate walking leg 1 . Once a decision to switch host is made, and having both shells in proximity, the rest of the body is rapidly removed from one shell and inserted, abdomen first, into the new host shell in fewer than 5 seconds.

\section{Discussion}

Some behaviors exhibited during this experiment offered insights into how these organisms investigate and decide on a shell to occupy. Even though efforts were made to acclimate individual $P$. longicarpus to living without a shell, the tendency to look for a shell to serve as house was so strong that over half of the tested hermit crabs occupied any available shell with minimal investigation within the first five minutes. This may explain why fewer $P$. longicarpus chose untreated shells when light acid damage shells were provided (Figure 4, blue line).

Interestingly, a few hermit crabs switched back to acid treated shells throughout the duration of the experiments. These switches back to weakened shells can most likely be attributed to the P. longicarpus shell investigation and selection processes (Rotjan et al. 2004). Although P. longicarpus hermit crabs appear to detect superficial (in light acid treatments) and structural degradation (in heavy acid treatments), these crabs may still occupy compromised shells to determine how well a shell will fit the individual. This behavior appears to occur less often in situ, as there are chemical effluents from potential predators (Rotjan et al. 2004), as well as strong intraspecific competition for the most protective shells (Carson and Ebersole 1995).

Figure 5 illustrates the shell structure of control, lightly acidified, and heavily acidified shells. Control shells (Figure 5) have a whitish, presumably calcareous, layer on the aperture although I am not sure if it is a natural part of the shell or caused external environmental phenomena. In contrast, the acidified shells (Figures 6 and 7), lack this whitish layer and have beige and orange brown bands. One testable hypothesis is that $P$. longicarpus hermit crabs use differences in aperture texture and/or chemistry for shell selection. 

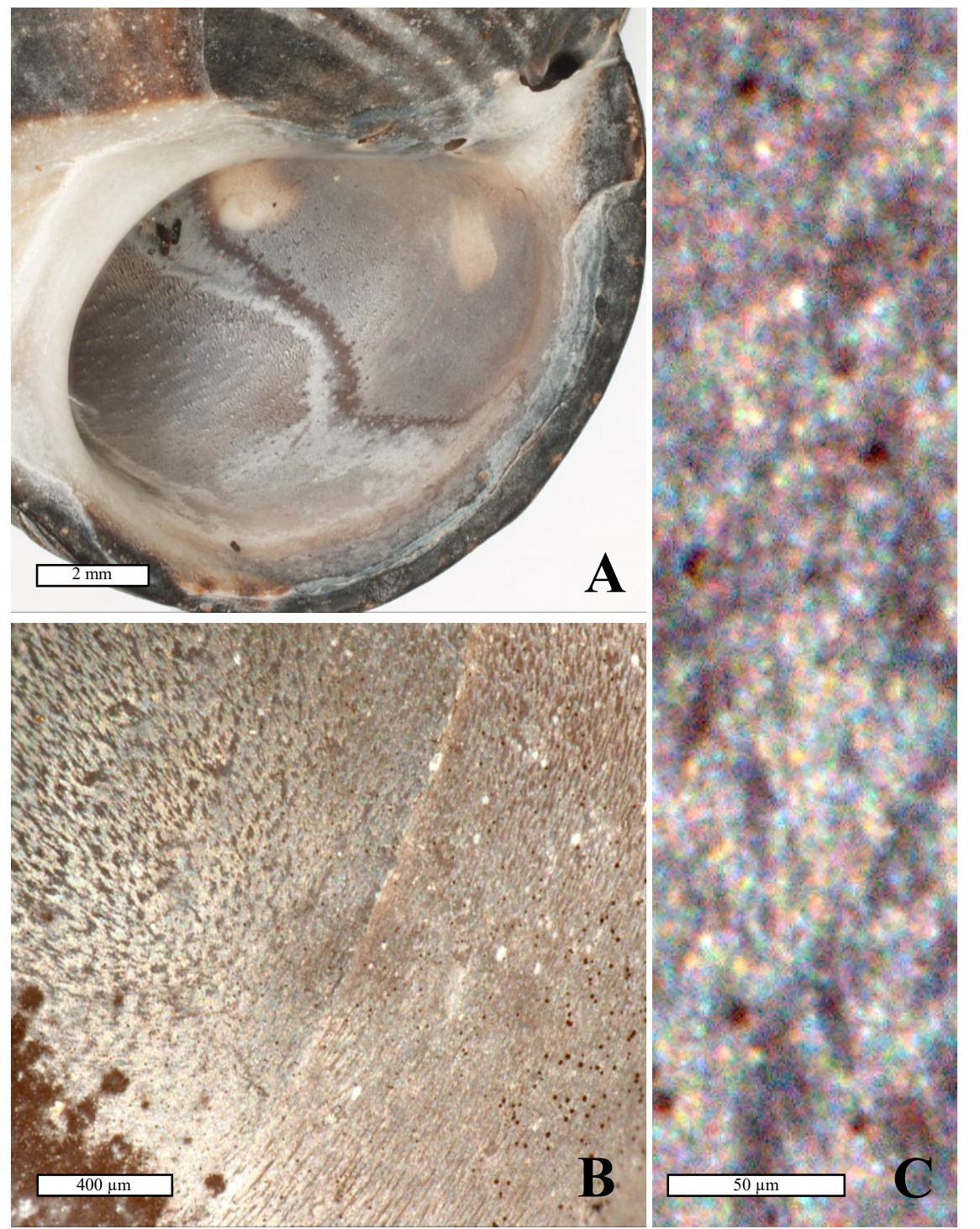

Figure 5. Light micrographs of the aperture of a representative untreated (control) Littorina littorea shell. A. Overall view. B. Medium magnification. C. Higher magnification. 

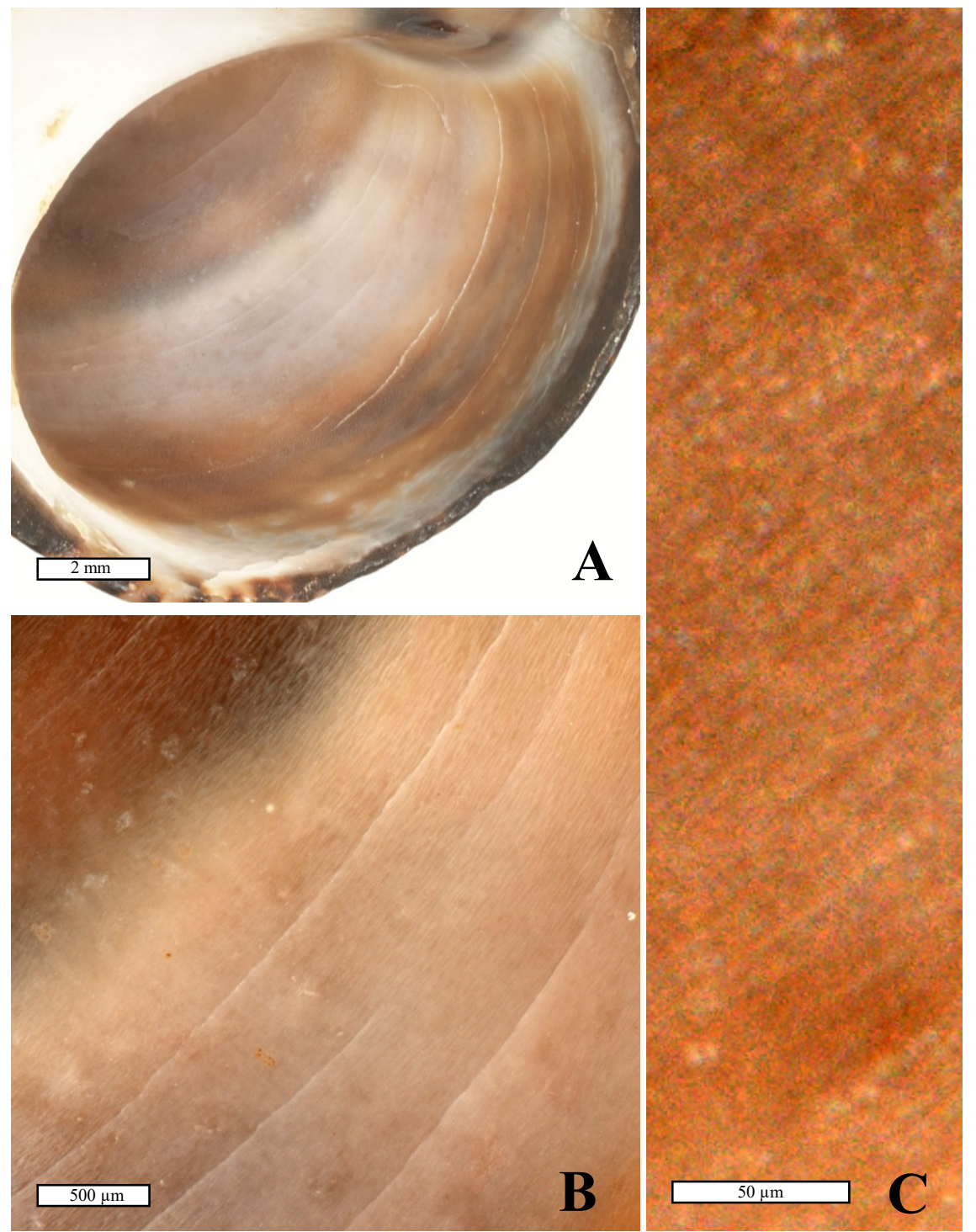

Figure 6. Light micrographs of the aperture of a representative lightly acid-treated Littorina littorea shell. See text for treatment details. A. Overall view. B. and C. Closeups. 


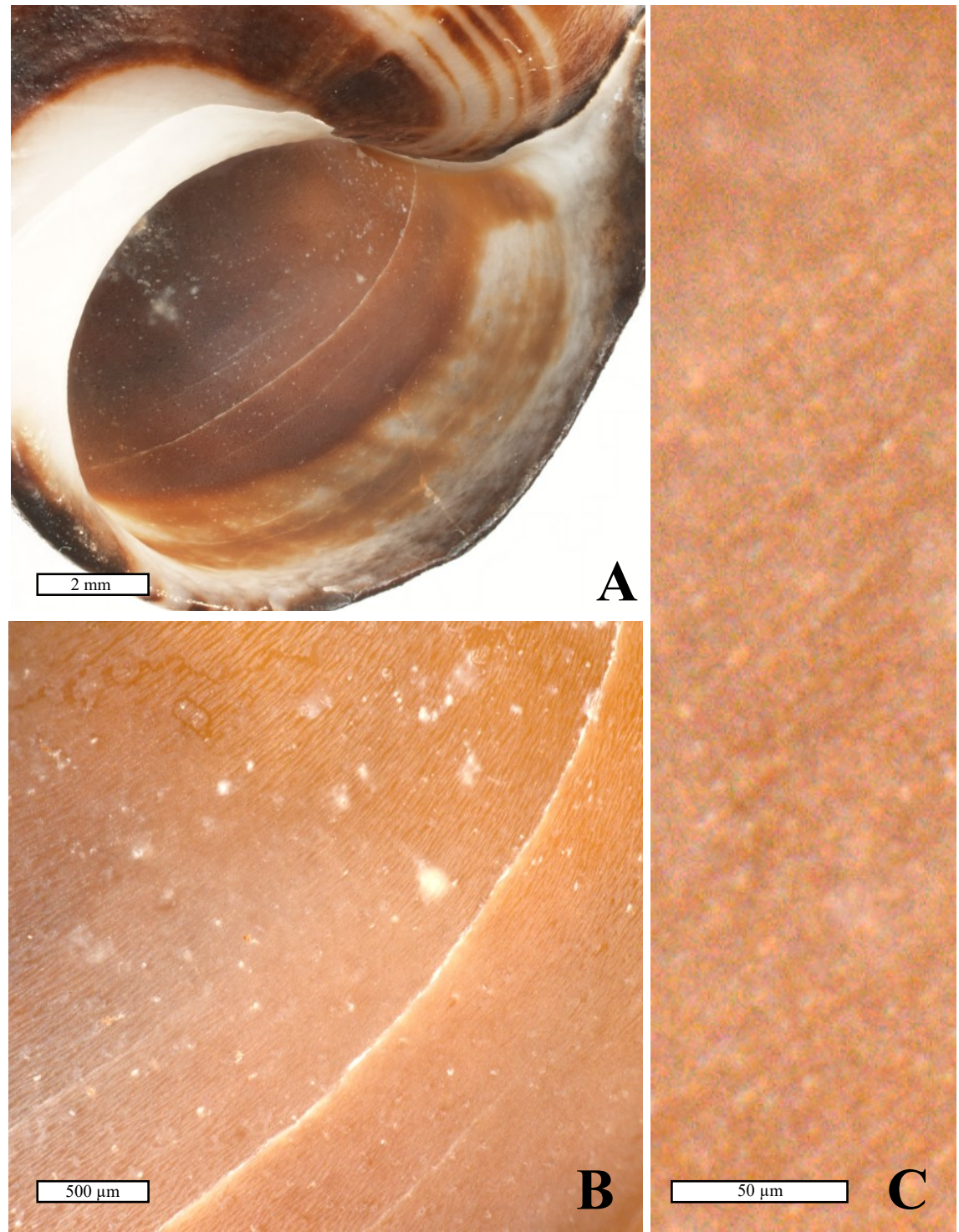

Figure 7. Light micrographs of the aperture of a representative strongly acid-treated Littorina littorea shell. See text for treatment details. A. Overall view. B. and C. Closeups. 


\section{Future Work}

Finding vacant shells is a relatively rare event in the lives of aquatic hermit crabs, such as $P$. longicarpus. Because aquatic hermit crabs seem to preferentially select heavier shells (Alcaraz et al. 2015, see Hsu et al. 2018 for a contrasting view on terrestrial hermit crabs), higher frequencies of intraspecific competition are likely to occur as some shells degrade from acidified water conditions. Stronger crabs will tend to inhabit thicker shells, while weaker crabs will be stuck with structurally compromised shells, putting them at higher risk of predation and osmotic stress (De la Haye et al. 2011). This competition may select for individuals of $P$. longicarpus that develop more effective means of shell theft and/or grow more rapidly. However, ocean acidification has been linked to slower growth rates in some crustaceans, so it will be interesting to determine how these two selections pressures interact (Whiteley 2011).

Similarly, future studies pertaining should investigate the effects of ocean acidification on shell selection behavior of different sized individuals of $P$. longicarpus, males vs. females, and on different species of hermit crabs. Given that surface area to volume ratio is highest at small scales, smaller shells will suffer from higher dissolution rates, a trend that was also noticed during the acid treatments for this study. Therefore, it stands to reason that smaller species of hermit crabs may exhibit stronger preference and competition for intact shells. These need for intact shells justifies extra energy expenditure to carry around larger ill-fitting shells that are not as susceptible to major acid dissolution. Furthermore, if this hypothesis is supported, selection pressures may also favor populations of larger, faster growing hermit crabs in the wild as smaller ones are more easily preyed upon (Carlon and Ebersole 1995). Nonetheless, studies of this nature should be wary of the consequences acidified water conditions have on the physiology of these crustaceans (Whiteley 2011).

Studies that aim to understand behavioral adaptations in response to all environmental stresses, including ocean acidification, are becoming more important as the benefits of high biodiversity are elucidated. With further knowledge on individual species' behavioral changes, we can ultimately begin to predict how these changes will influence community wide population dynamics in the hopes of improving our management strategies (Nagelkerken and Munday 2015). Based on the results of this study showing that ocean acidification and a consequent weakening of calcified shell structure has a significant influence on $P$. longicarpus shell selection, one would logically conclude that these changes will have profound influence on the ecosystem, since these abundant organisms are prey for a variety of species. As current predictions on future ocean acidification estimate greater changes to ocean $\mathrm{pH}$ in both the near and distant future (Vézina et al. 2008), our ability to predict these adaptations will be crucial for maintaining stability in these communities. 


\section{Acknowledgements}

Professor Jan A. Pechenik (Tufts University) introduced me to the topic of hermit crab shell selection behavior. Four anonymous reviewers and five anonymous statisticians offered numerous suggestions. Paul Callomon and Michelle Gannon (both at the Academy of Natural Science of Drexel University, Philadelphia, Pennsylvania, USA) confirmed the identification of the shells and offered constructive criticism. Dr. M. Schwinghammer (Alexandria, Virginia, USA) offered numerous comments on earlier versions of this paper. Also, I would like to thank Bess Miller, Nicholas Leigh, Garrett Dunlap, and Andrew Murphy (all at Harvard Medical School, Cambridge, Massachusetts, USA) for their assistance in animal collection and shell removal.

\section{Literature Cited}

Alcaraz, G., C. E. Chávez-Solís, and K. Kruesi. 2015. Mismatch between body growth and shell preference in hermit crabs is explained by protection from predators. Hydrobiologia 743(1): 151-156. https://doi.org/10.1007/s10750-014-2029-8

Anonymous. 2015. Amazing Crabs Shell Exchange. Life Story. BBC Earth. 4'15" https://www.youtube.com/watch?v=fldnocPQXDQ [A computer literature search using Google, indicates that there are nearly 49,000 videos on the topic "hermit crab" on the web.]

Anonymous. 2018. Crafty Hermit Crab Finds a New Home in a Food Tin. BBC Earth. 3'51" https://www.youtube.com/watch?v=LuwQKJCO9UQ

Bibby, R., P. Cleall-Harding, S. Rundle, S. Widdicombe, and J. Spicer. 2007. Ocean acidification disrupts induced defenses in the intertidal gastropod Littorina littorea. Biology Letters 3(6):699-701. https://doi.org/10.1098/rsbl.2007.0457

Briffa, M. 2006. Signal residuals during shell fighting in hermit crabs: can costly signals be used defensively? Behavioral Ecology 17(3):510-514. https://doi.org/10.1093/beheco/arj059

Busch, D. S., M. Maher, P. Thibodeau, P. McElhany. 2014. Shell condition and survival of Puget sound pteropods are impaired by ocean acidification conditions. PLOS ONE 9(8):2-12. https://doi.org/10.1371/journal.pone.015884

Carlon D. B. and J. P. Ebersole. 1995. Life-history variation among three temperate hermit crabs: the importance of size in reproductive strategies. Biological Bulletin 188:329-337. https://doi.org/10.2307/1542309

De la Haye, K. L., J. I. Spicer, S. Widdicombe, and M. Briffa. 2011. Reduced sea water pH disrupts resource assessment and decision making in the hermit crab Pagurus bernhardus. Animal Behaviour 82:495-501. https://doi.org/10.1016/j.anbehav.2011.05.030

Gherardi, F. 2006. Fighting behavior in hermit crabs: the combined effect of resource-holding potential and resource value in Pagurus longicarpus. Behavioral Ecology \& Sociobiology 59(4):500-510. https://doi.org/10.1007/s00265-005-0074-z

Hazlett B. A. 1981. The behavioral ecology of hermit crabs. Annual Review of Ecology, Evolution, and Systematics 12:1-22. https://doi.org/10.1146/annurev.es.12.110181.000245

Hoegh-Guldberg, O. and J. F. Bruno. 2010. The impact of climate change on the world's marine ecosystems. Science 328(5985):1523-1528. https://doi.org/10.1126/science.1189930

Hsu, C.-H., M. L. Otte, C.-C. Liu, J.-Y. Chou, and W.-T. Fang. 2018. What are the sympatric mechanisms for three species of terrestrial hermit crab (Coenobita rugosus, C. brevimanus, and C. cavipes) in coastal forests? PLoS One 13(12):e0207640. https://doi.org/10.1371/journal.pone.0207640

Leung, J. Y. S., S. D. Connell, I. Nagelkerken, B. D. Russell. 2017. Impacts of near-future ocean acidification and warming on the shell mechanical and geochemical properties of gastropods from intertidal to subtidal zones. Environmental Science \& Technology 51(21):12097-12103. https://doi.org/10.1021/acs.est.7b02359

Nagelkerken, I. and P. M. Munday. 2015. Animal behaviour shapes the ecological effects of ocean acidification and warming: moving from individual to community level responses. Global Change Biology 22(3):974-989. https://doi.org/10.1111/gcb.13167

Orr, J. C., V. J. Fabry, O. Aumont, L. Bopp, S. C. Doney, R. A. Feely, A. Gnanadesikan, N. Gruber, A. Ishida, F. Joos, R. M. Key, K. Lindsay, E. Maier-Reimer, R. Matear, P. Monfray, A. Mouchet, R. G. Najjar, G-K. Plattner, K. B. Rodgers, C. L. Sabine, J. L. Sarmiento, R. 
Schlitzer, R. D. Slater, I. J. Totterdell, M.-F. Weirig, Y. Yamanaka, and A. Yool. 2005. Anthropogenic ocean acidification over the twenty-first century and its impact on calcifying organisms. Nature 437; 681-686. https://doi.org/10.1038/nature04095

Pechenik, J. A. and S. M. Lewis. 2000. Avoidance of drilled gastropod shells by the hermit crab Pagurus longicarpus at Nahant, Massachusetts. Journal of Experimental Marine Biology and Ecology 253(1):17-32. https://doi.org/10.1016/S0022-0981(00)00234-3

Rotjan, R. D., S. M. Lewis, and J. Blum. 2004. Shell choice in Pagurus longicarpus hermit crabs: does predation threat influence shell choice behavior. Behavioral Ecology and Sociobiology 56(2): 171-176. https://doi.org/10.1007/s00265-004-0770-0

Singer, F. D. 2016. Ecology in Action. Cambridge University Press. Cambridge, England, United Kingdom. 706 pp.

Vézina, A.F. and O. Hoegh-Guldberg. 2008. Effect of ocean acidification on marine ecosystems. Marine Ecology Progress Series 373:199-202. https://doi.org/10.3354/meps07868

Whiteley, N. N. 2011. Physiological and ecological responses of crustaceans to ocean acidification. Marine Ecology Progress Series 430:257-271. https://doi.org/10.3354/meps09185

Zeebe, R. E., J. C. Zachos, K. Caldeira, T. Tyrrell. 2008. Carbon emissions and acidification. Science 321: 51-52. https://doi.org/10.1126/science.1159124 